\title{
Antiproliferative Effects of Octadecyloxyethyl 9-[2-(Phosphonomethoxy)Ethyl]Guanine against Me-180 Human Cervical Cancer Cells in vitro and in vivo
}

\author{
Nadejda Valiaeva Julissa Trahan Kathy A. Aldern James R. Beadle \\ Karl Y. Hostetler \\ Department of Medicine, University of California, San Diego, La Jolla, Calif., and Veterans Medical Research \\ Foundation, San Diego, Calif., USA
}

\section{Key Words}

Cervical cancer $\cdot$ Acyclic nucleoside phosphonates $\cdot$ Ether lipid prodrugs

\begin{abstract}
Background/Aims: 9-[2-(phosphonomethoxy)ethyl]guanine (PMEG) is one of the most active antiproliferative compounds in a series of acyclic nucleoside phosphonates and is active in intraperitoneal P388 tumors in mice. Methods: We synthesized octadecyloxyethyl (ODE) and hexadecyloxypropyl esters of PMEG and compared their antiproliferative activity with unmodified PMEG in primary human fibroblasts and CaSki, Me-180 and HeLa human cervical cancer cell lines in vitro. Results: ODE-PMEG had excellent antiproliferative activity in vitro in this panel of human cervical cancers. We compared the effects of ODE-PMEG and ODE-cidofovir (ODE-CDV) in a solid tumor model using Me-180 human cervical cancer cell lines in athymic nude mice. Intratumoral injection of $25 \mu \mathrm{g}$ of ODE-PMEG or $100 \mu \mathrm{g}$ of ODE-CDV daily for 21 days followed by observation for 20-35 days resulted in near-complete disappearance of measurable cervical cancers. Conclusion: ODE-PMEG may be suitable for local or topical treatment of cervical dysplasia.
\end{abstract}

Copyright $\odot 2010$ S. Karger AG, Basel

\section{KARGER}

Fax +41613061234 E-Mail karger@karger.ch www.karger.com
(C) 2010 S. Karger AG, Basel

$0009-3157 / 10 / 0561-0054 \$ 26.00 / 0$

Accessible online at:

www.karger.com/che

\section{Introduction}

The acyclic nucleoside phosphonate (S)-1-[3-hydroxy2-(phosphonylmethoxy)-propyl]-cytosine (cidofovir, CDV) has been reported to selectively inhibit the proliferation of human papillomavirus DNA+ cancer cells in vitro [1-5], in animals [2] and in men [6]. CDV is reported to reduce levels of the E6 oncoprotein resulting in an increase in p53 and pRb, allowing the cell to regain control of the cell cycle, slowing proliferation and leading to apoptosis [2-4].

The antiviral activity of CDV against several doublestranded DNA viruses (human cytomegalovirus, vaccinia, cowpox) can be increased several logs by esterification with alkoxyalkyl groups such as hexadecyloxypropyl (HDP) or octadecyloxyethyl (ODE) [7-10]. This was shown to be due to greatly increased cell entry of the lipid-modified drug and higher intracellular levels of CDVdiphosphate, the active inhibitor of viral DNA polymerases [11]. Similar results were noted with HDP esters of (S)-HPMPA in HIV-1-infected cells [12-14]. As noted above, CDV has been reported to be strongly antiproliferative against cervical cancer cells [1-5]. We studied the effect of ODE-CDV and several other CDV analogs on the proliferation of primary fibroblast and human cervi-

Tel. +1 858552 8585, ext. 2616, Fax +1 858534 6133, E-Mail khostetl@ ucsd.edu 
Fig. 1. Structures of ODE-CDV and ODEPMEG.

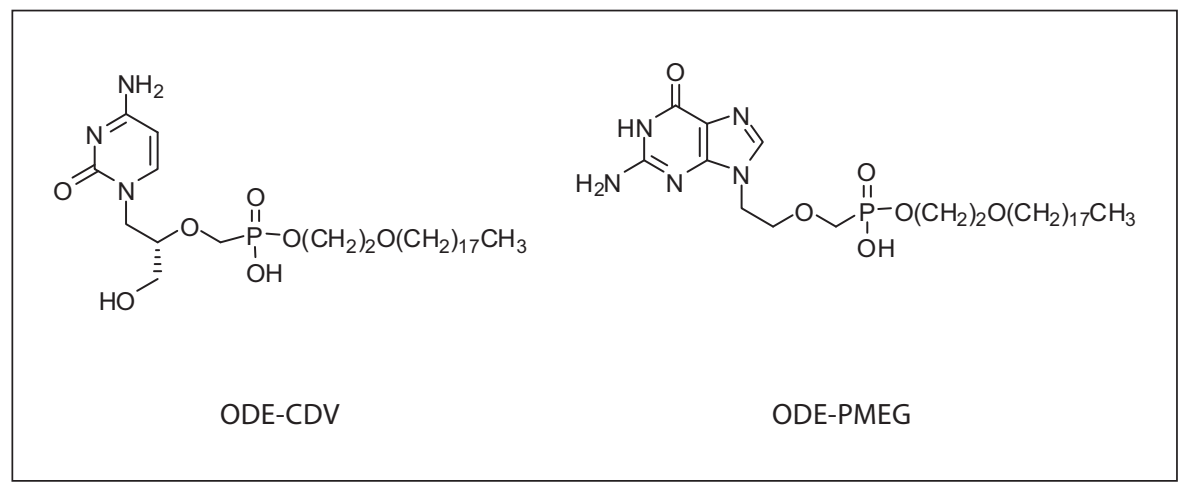

cal cancer cell lines in vitro. ODE-CDV was several logs more active in inhibiting proliferation of cervical cancer cells than CDV and showed 2.5- to 140-fold selectivity for cervical cancer cells versus normal human foreskin fibroblast (HFF) cells [1].

Recently, we synthesized the HDP and ODE esters of a series of other acyclic nucleoside phosphonates including 9-[2-(phosphonomethoxy)ethyl]guanine (PMEG) and tested them for antiviral activity against HIV-1 in human T lymphoblastic leukemia cell lines, CEM and MT-2. As part of the antiviral assessment, we carried out in vitro cytotoxicity assessments and observed that ODEPMEG was highly antiproliferative in MT-2 cells with a $50 \%$ inhibitory concentration $\left(\mathrm{IC}_{50}\right)$ of $1 \times 10^{-7} \mu \mathrm{M}$. $\mathrm{IC}_{50}$ in CEM-SS cells was $6 \times 10^{-5} \mu \mathrm{M}$ [15]. Although ODEPMEG appeared to be highly active in HIV-1-infected cells, the selectivity index was very low and it was concluded that the apparent antiviral effect could be explained by the marked antiproliferative effects of ODEPMEG [15]. To see if these findings extend to rapidly dividing human cervical cancer cells, we evaluated the antiproliferative activity of unmodified PMEG, HDPPMEG and ODE-PMEG in three human cervical cancer cell lines, CaSki, Me-180 and HeLa, and in normal HFF cells. Finally, we implanted Me-180 cervical cancer cells in the flank of athymic nude mice, allowed solid tumors to form and assessed the antitumor effects of local injections of ODE-CDV and ODE-PMEG in vivo.

\section{Materials and Methods}

Synthesis of Alkoxyalkyl Esters of PMEG

HDP-PMEG and ODE-PMEG were synthesized, purified and characterized as previously described [15]. The synthesis and evaluation of HDP-CDV and ODE-CDV have been reported previously $[7,14]$. Purity of the compounds used in this study was assessed at $>98 \%$. The proton nuclear magnetic resonance and mass spectroscopy data for these compounds have been reported previously $[7,10,15]$. The structures of ODE-CDV and ODEPMEG are shown in figure 1.

\section{Cell Lines and Cell Culture}

Normal HFF cells (CRL-1634, Hs27) were obtained from the American Type Culture Collection (Manassas, Va., USA) and maintained in minimum essential medium containing $10 \%$ fetal bovine serum (Gibco, Grand Island, N.Y., USA). Cervical cancer cell lines associated with the HPV subtypes 16, 68 and 18, CaSki (CRL-1550), Me-180 (HTB-33) and HeLa (CCL-2) were also obtained from the American Type Culture Collection and maintained in McCoy's 5A medium or minimum essential medium containing $10 \%$ fetal bovine serum [1].

\section{Cell Proliferation Assays}

Cell lines were plated at $5 \times 10^{3}$ per well in 96 -well plates using media with $10 \%$ fetal bovine serum added and incubated for about $24 \mathrm{~h}$ as described previously [1]. A $10 \mathrm{mM}$ stock solution of PMEG was prepared in water; $10 \mathrm{mM}$ stocks of HDP-PMEG and ODE-PMEG were prepared in $10 \%$ DMSO in distilled water. Serial drug dilutions were made in media containing $2 \%$ fetal bovine serum to give a final concentration of $6 \%$ fetal bovine serum, added to the wells, and incubated at $37^{\circ} \mathrm{C}$ for 5 days. Determination of cell proliferation was performed using an XTT Cell Proliferation Kit II according to the manufacturer's instructions (Roche Molecular Biochemicals, Mannheim, Germany). Briefly, the reagents were mixed and added to the wells and placed on a shaker for $15 \mathrm{~min}$ followed by incubation at $37^{\circ} \mathrm{C}$ for approximately 30 min. $\mathrm{OD}_{450}$ was determined using an ELISA plate reader (Biotek Instruments, Winooski, Vt., USA). The data were plotted and $\mathrm{IC}_{50}$ was assessed using graphing software (Prizm, GraphPad Software, San Diego, Calif., USA).

\section{Me-180 Tumors in Athymic Nude Mice}

Female athymic nude Balb/c mice (Charles River) were injected subcutaneously with $5 \times 10^{6} \mathrm{Me}-180$ cervical cancer cells. The tumors were allowed to become established for 14 days. Tumor measurements were then taken by calipers to measure two dimensions of the tumor in millimeters. These dimensions were multiplied to assess total tumor volume. Baseline tumor volume measurements were approximately $30-35 \mathrm{~mm}$. Mice were then ran- 


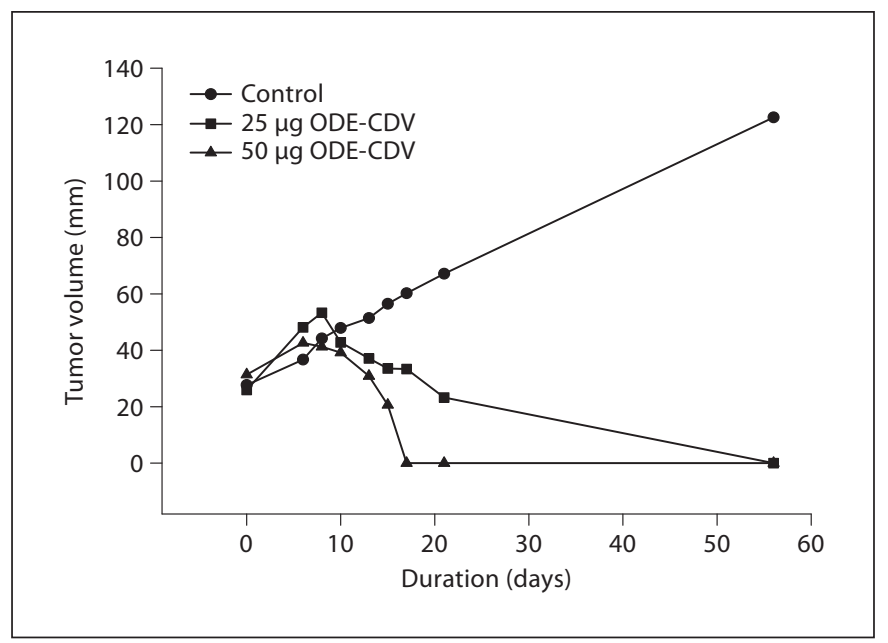

Fig. 2. Effect of daily intratumoral injections of ODE-CDV for 21 days on Me-180 tumors in vivo.

domized into three groups of 8 mice each and treated with intratumor injection of $0.9 \%$ saline or the indicated doses of ODECDV or ODE-PMEG. The intratumor injection volume was $50 \mu \mathrm{l}$. Tumor size measurements and body weights were taken 3 times a week for the indicated times. In the ODE-CDV experiments, tumor-bearing mice were dosed by intratumoral injection of $50 \mu \mathrm{g}$ $(2 \mathrm{mg} / \mathrm{kg})$ or $100 \mu \mathrm{g}(4 \mathrm{mg} / \mathrm{kg})$ daily for 21 days. Body weight and tumor size were assessed 3 times a week to day 21. After treatment was stopped the animals were maintained until day 56 when tumor size was reassessed (fig. 2). In the experiments with ODEPMEG, animals were dosed by intratumoral injection of $25 \mu \mathrm{g}$ $(1 \mathrm{mg} / \mathrm{kg})$ or $12.5 \mu \mathrm{g}(0.5 \mathrm{mg} / \mathrm{kg})$ of ODE-PMEG as indicated for 21 days while the control mice received $0.9 \%$ saline solution. Tumor size was measured 3 times weekly for 40 days (fig. 3).

\section{Results}

The antiproliferative activity of PMEG was evaluated after a 5-day exposure in primary HFF cells and in $3 \mathrm{hu}-$ man cervical cancer cell lines using the XTT cell proliferation assay and $\mathrm{IC}_{50}$ was assessed and compared with HDP-PMEG and ODE-PMEG (table 1). In most cervical cancer cell lines, HDP-PMEG and ODE-PMEG were 600-400,000 times more inhibitory than unmodified PMEG. An exception was seen with HDP-PMEG in Me180 cells. In normal HFF cells, smaller 3- to 9-fold increases in antiproliferative activity were noted for HDPPMEG and ODE-PMEG versus the very low $\mathrm{IC}_{50}$ values noted in the cervical cancer cell lines.

We compared the antiproliferative activity of ODEPMEG with that reported previously for ODE-CDV in

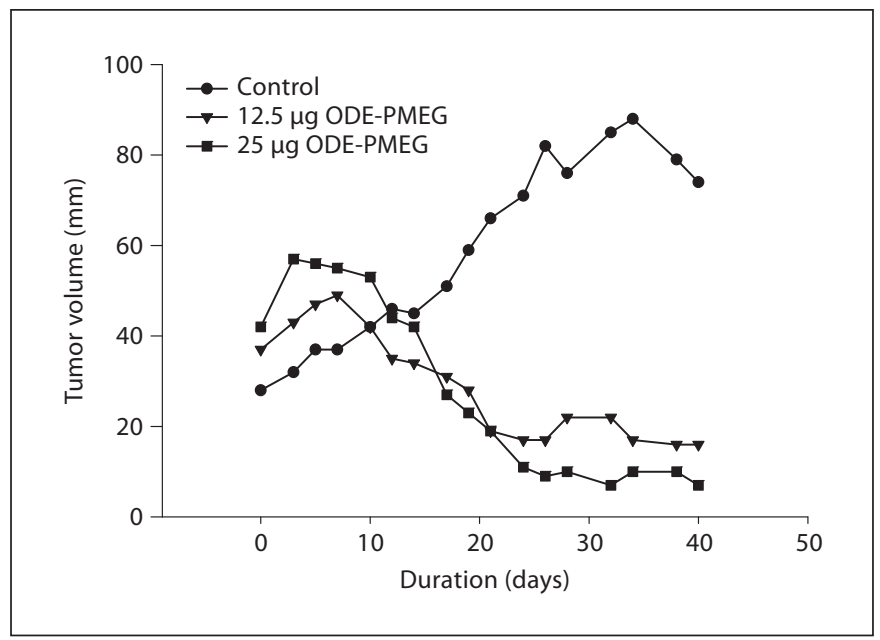

Fig. 3. Effect of daily or every-other-day intratumoral injections for 21 days of ODE-PMEG on Me-180 solid tumors in athymic nude mice in vivo.

Table 1. Antiproliferative activity of PMEG, HDP-PMEG and ODE-PMEG in primary HFF cells and CaSKi, Me-180, and HeLa cervical cancer cells in vitro

\begin{tabular}{|c|c|c|c|}
\hline Cell type/drug & $\mathrm{IC}_{50}, \mu \mathrm{M}$ & $\begin{array}{l}\text { Fold } \\
\text { diff. }\end{array}$ & $\begin{array}{l}\text { Selectivity } \\
\text { for cervical } \\
\text { cancer cells }\end{array}$ \\
\hline \multicolumn{4}{|l|}{ Primary HFF cells } \\
\hline PMEG & $45 \pm 42(2)$ & - & - \\
\hline HDP-PMEG & $18 \pm 21(3)$ & 2.5 & - \\
\hline ODE-PMEG & $5.0 \pm 1.7(3)$ & 9.0 & - \\
\hline \multicolumn{4}{|c|}{ CaSki cells (HPV 16) } \\
\hline PMEG & $18 \pm 3.2(3)$ & - & 2.5 \\
\hline HDP-PMEG & $0.027 \pm 0.01(3)$ & 667 & 667 \\
\hline ODE-PMEG & $0.002 \pm 0.003(6)$ & 9,000 & 2,500 \\
\hline \multicolumn{4}{|c|}{ Me-180 cells (HPV 68) } \\
\hline PMEG & $9.3 \pm 2.5(3)$ & - & 4.8 \\
\hline HDP-PMEG & $11.4 \pm 6.9(3)$ & 0.8 & 1.6 \\
\hline ODE-PMEG & $0.002 \pm 0.003(3)$ & 4,650 & 2,500 \\
\hline \multicolumn{4}{|c|}{ HeLa cells (HPV 18) } \\
\hline PMEG & $14.4 \pm 11.5(4)$ & - & 3.1 \\
\hline HDP-PMEG & $5 \times 10^{-4} \pm 5 \times 10^{-4}(4)$ & 28,800 & 36,000 \\
\hline ODE-PMEG & $3.5 \times 10^{-5} \pm 1 \times 10^{-4}(3)$ & 411,000 & 143,000 \\
\hline
\end{tabular}

$\mathrm{IC}_{50}$ reduces viable cell number by $50 \%$ in XTT cell proliferation assay. The $\mathrm{IC}_{50}$ data are means $\pm \mathrm{SD}$. The numbers in parentheses are the number of replicates. Selectivity of the various drugs for cancer cells versus primary HFF cells (Selectivity $=\mathrm{IC}_{50}$ $\mathrm{HFF} / \mathrm{IC}_{50}$ cancer cell). Fold difference is the fold increase in antiproliferative activity versus the unmodified nucleotide drug. 
Table 2. Comparison of the antiproliferative effects of ODE-CDV with ODE-PMEG in primary HFF cells and in human cervical cancer cell lines CaSki, Me-180 and HeLa

\begin{tabular}{lllll}
\hline \multirow{2}{*}{ Drug } & \multicolumn{2}{l}{$\mathrm{IC}_{50}, \mu \mathrm{M}$} & & \\
\cline { 2 - 5 } & $\mathrm{HFF}$ & CaSki & Me-180 & HeLa \\
\hline CDV & 853 & 910 & 627 & 516 \\
ODE-CDV & 4.2 & 1.7 & 0.39 & 0.03 \\
PMEG & 45.0 & 18.0 & 9.3 & 14.4 \\
ODE-PMEG & 5.0 & 0.002 & 0.002 & $3.5 \times 10^{-5}$ \\
\hline
\end{tabular}

CDV and ODE-CDV data are from Hostetler et al. [1]. PMEG and ODE-PMEG data are from table 1.

HFF cells and cervical cancer cell lines [1]. In primary HFF cells, ODE-CDV and ODE-PMEG had comparable $\mathrm{IC}_{50}$ values, 4.2 and $5.0 \mu \mathrm{M}$ (table 2). However, in human cervical cancer cells in vitro, ODE-PMEG was substantially more inhibitory than ODE-CDV: 850 -fold greater in CaSki cells, 195-fold greater in Me-180 and 857-fold greater in HeLa cells (table 2). ODE-PMEG was the most active compound with $\mathrm{IC}_{50}$ values in cervical cancer cells ranging from 0.035 to $2 \mathrm{nM}$ (table 2). This represents preferential proliferation inhibition by ODE-PMEG of human cervical cancer cells of $>2,500$ versus the $\mathrm{IC}_{50}$ values in primary HFF cells.

Me-180 human cervical cancer cells were injected into the flanks of athymic nude mice and after the tumor size had reached $20-30 \mathrm{~mm}$ (about $5 \times 5 \mathrm{~mm}$ ), animals were treated daily for 21 days by intratumoral injection of $0.9 \%$ saline or with $2 \mathrm{mg} / \mathrm{kg}(50 \mu \mathrm{g})$ or $4 \mathrm{mg} / \mathrm{kg}(100 \mu \mathrm{g})$ of ODE-CDV. Tumor size was estimated for 21 days and after cessation of treatment, animals were maintained and tumor size evaluated after 56 days (fig. 2). Control tumors injected daily with $0.9 \%$ saline grew progressively to $67 \mathrm{~mm}$ by day 21 . Me- 180 cervical cancers treated with 50 or $100 \mu \mathrm{g}$ per day of ODE-CDV continued to grow for the first 10 days at a rate similar to controls. However, by day 13 , a rapid decline in tumor size was noted in the 100 $\mu \mathrm{g}$ per day group and by day 17 all tumors had disappeared leaving normal-appearing skin at day 56. In the group treated with $50 \mu \mathrm{g} /$ day of ODE-CDV, tumor size decreased gradually by day 21 to about $30 \%$ of the size of control tumors. Treatment was stopped and the animals were observed. The tumors gradually decreased in size and by day 56 , none of the animals had remaining tumor. Control tumor measurements had increased linearly to $122 \mathrm{~mm}$ on day 56 . Body weight of the controls increased
$7.1 \%$ by day 21 versus a loss of body weight of -3.6 and $-8.2 \%$ in the 50 and $100 \mu \mathrm{g} /$ day treatment groups, respectively. However, by day 56, both ODE-CDV-treated groups had regained their starting weights.

ODE-PMEG is several logs more active than ODE$\mathrm{CDV}$ in various human cervical cancer cell lines in vitro (table 2). To compare the in vivo activity of ODE-CDV and ODE-PMEG, we treated Me-180 tumors for 21 days with daily intratumoral injections of ODE-PMEG or vehicle and measured tumor size and body weights 3 days per week up to 40 days at which time the experiment was terminated (fig. 3). Tumors treated with the normal saline vehicle increased progressively from 28 to $66 \mathrm{~mm}$ by day 21 and continued to grow to $88 \mathrm{~mm}$ at day 34 after which time they decreased slightly in volume. Tumors treated with $25 \mu \mathrm{g}$ daily increased in size for 10 days followed by a rapid decline in tumor volume to $19 \mathrm{~mm}$ at day 21 . After treatment was stopped, tumors in this group continued to decline in size. By day 40, 7 of 8 animals had no measurable tumor at the injection site. Similar results were noted at day 21 in the $12.5 \mu \mathrm{g}$ per day treatment group, but only 4 of 8 animals in this group had no measurable tumor at day 40 . At day 21 , the body weight of control animals decreased by $-4.5 \%$ versus -5.1 and $-10.4 \%$ in the 12.5 and $25 \mu \mathrm{g} /$ day groups, respectively. After the injections were stopped at day 21, all groups of animals regained weight and by day 40 the body weights of the control and treatment groups were not statistically different.

\section{Discussion}

Acyclic nucleoside phosphonates like CDV, (S)HPMPA and PMEG have limited cellular uptake and esterification with HDP and ODE groups has been shown to increase cell uptake by more than 100 -fold in vitro [11, $13,14]$. We first reported the synthesis of ODE-PMEG in 2006 as part of a survey of the ability of alkoxyalkyl esters of acyclic nucleoside phosphonates to inhibit HIV-1 replication in infected cells [15]. ODE-PMEG was highly cytotoxic in MT-2 lymphoblastic T cells with an $\mathrm{IC}_{50}$ value of $<1 \times 10^{-7} \mu \mathrm{M}$ while unmodified PMEG was at least 1,000 -fold less cytotoxic [15]. $\mathrm{IC}_{50}$ for ODE-PMEG in CEM-SS cells, a human T cell leukemia line, was $6 \times$ $10^{-5} \mu \mathrm{M}$; PMEG itself was previously reported to have an $\mathrm{IC}_{50}$ value of $0.7 \mu \mathrm{M}$ in CEM-SS cells [16]. Thus, ODEPMEG is several 1,000 -fold more antiproliferative than PMEG in CEM-SS cells in vitro.

We reported previously that ODE-CDV was many times more antiproliferative than unmodified CDV in a 
panel of human cervical cancer cell lines [1]. In this report, we compared ODE-CDV and ODE-PMEG against several human cervical cancer cell lines (table 1) and found them to be highly inhibitory to cervical cancer cell proliferation. ODE-PMEG was significantly more active than ODE-CDV by 195 -fold in Me-180 cervical cancer cells (table 2). The activity of ODE-PMEG in Me-180 solid tumors in athymic nude mice was also greater than ODE-CDV but only by a factor of 4 .

With regard to the mechanism of antitumor activity, PMEG has been shown to be the most active of the acyclic nucleoside phosphonates inducing antiproliferative effects in CEM-SS human lymphocytic leukemia cells in vitro [16] and was shown to be effective against intraperitoneal P338 leukemia in mice [17]. PMEG is metabolized by anabolic phosphorylation to PMEG diphosphate (PMEGpp), which is a potent inhibitor of human polymerases $\alpha$ and $\delta$ [18] and polymerase $\varepsilon$ [19]. PMEG can be incorporated into DNA and functions as an obligatory chain terminator; only polymerase $\varepsilon$ can repair the PMEG-terminated chain [19].

GS-9219 is a prodrug which gives rise intracellularly to PMEGpp. In chronic lymphocytic leukemia cells, PMEGpp is incorporated into DNA in response to ultraviolet activation, inhibiting DNA repair and leading to strand breaks and apoptosis [20]. These effects of PMEGpp are presumed to be the basis for its antitumor activity [18-20]. Wolfgang et al. [21] recently reported studies in cervical cancer cells with GS-9191, a prodrug which gives rise intracellularly to PMEG after hydrolysis of isopropylphenylalanyl protecting groups on the phosphonate followed by deamination to PMEG. PMEG is converted by anabolic phosphorylation to PMEGpp, the active metabolite. GS-9191 inhibited proliferation of various human cervical cancer cell lines with $\mathrm{IC}_{50}$ values ranging from 0.03 to $284 \mathrm{nM}$ [21].

ODE-PMEG has antiproliferative activity equivalent to, or more active than GS-9191 in 3 cervical cancer cell lines which were studied by both Wolfgang et al. [21] and in this report (table 3). In CaSki cells and Me-180 cells, the observed $\mathrm{IC}_{50}$ values for GS-9191 and ODE-PMEG were comparable at $2 \mathrm{nM}$. In HeLa cells, however, the $\mathrm{IC}_{50}$ value of ODE-PMEG was $0.035 \mathrm{nM}$ versus $0.71 \mathrm{nM}$ for GS-9191, representing an increase in antiproliferative activity of 20 -fold. Interestingly, in some cervical cancer cell lines, conversion of GS-9191 to its active form may be slow despite good cellular uptake of the double prodrug [21]. In contrast, ODE-PMEG requires only one cleavage by a phospholipase-C-like enzyme as shown previously with related ODE and HDP esters of acyclic nucleoside
Table 3. Comparison of the antiproliferative activity of ODEPMEG and GS-9191 in cervical cancer cell lines in vitro

\begin{tabular}{lll}
\hline Cervical cancer cell line & $\mathrm{IC}_{50}, \mathrm{nM}$ \\
\cline { 2 - 3 } & ODE-PMEG & GS-9191 $^{\mathrm{a}}$ \\
\hline CaSki & 2.00 & 2.03 \\
HeLa & 0.035 & 0.71 \\
Me-180 & 2.00 & 1.83 \\
\hline
\end{tabular}

${ }^{\text {a }}$ Data are from Wolfgang et al. [21].

phosphonates [11, 13, 14]. Although ODE-PMEG carries one negative charge while GS-9191 is neutral, cell uptake of ODE-PMEG is not by passive diffusion but by active association and insertion into the cell membrane's lipid bilayer followed by transbilayer movement and desorption from the inner leaflet of the plasma membrane [14], an ideal strategy for a topical agent. Although the present in vivo studies were done by injecting test compounds directly into solid tumors, we found previously that topical applications of ODE-CDV were effective in treating cutaneous vaccinia infection in athymic nude mice [J. Neyts, E. De Clercq and K.Y. Hostetler, unpublished data]. This suggests that topical treatment of cervical dysplasia might be possible with these agents. The basis for the increased antitumor activity of ODE-PMEG has not been studied in depth but is likely to be due to increased cellular uptake and conversion of ODE-PMEG to PMEGpp as demonstrated previously for alkoxyalkyl esters of CDV and (S)-HPMPA [11, 13, 14] and for PMEG resulting from the cellular metabolism of GS-9219 [20] and GS-9191 [21].

In conclusion, ODE-PMEG has excellent antiproliferative activity against several cervical cancer cell lines in vitro. In vivo, it is highly active against Me-180 solid tumors in athymic nude mice. ODE-PMEG is worthy of further research and development and may prove useful for local or topical treatment of cervical dysplasia.

\section{Acknowledgements}

This work was supported in part by NIH grants CA-105039 from the National Cancer Institute, AI-071803 and AI-074057 from the National Institute of Allergy and Infectious Disease and by the San Diego Veterans Medical Research Foundation. 


\section{References}

-1 Hostetler KY, Rought S, Aldern KA, Trahan J, Beadle JR, Corbeil J: Enhanced antiproliferative effects of alkoxyalkyl esters of cidofovir in human cervical cancer cells in vitro. Mol Cancer Ther 2006;5:156-159.

$\checkmark 2$ Abdulkarim B, Sabri S, Deutsch E, Chagraoui H, Maggiorella L, Thierry J, Eschwege F, Vainchenker W, Chouaïb S, Bourhis J: Antiviral agent cidofovir restores p53 function and enhances the radiosensitivity in HPVassociated cancers. Oncogene 2002;21:23342346.

-3 Andrei G, Snoeck R, Piette J, Delvenne P, De Clercq E: Antiproliferative effects of acyclic nucleoside phosphonates on human papillomavirus (HPV)-harboring cell lines compared with HPV-negative cell lines. Oncol Res 1998; 10:523-531.

-4 Andrei G, Snoeck R, Schols D, De Clercq E: Induction of apoptosis by cidofovir in human papillomavirus (HPV)-positive cells. Oncol Res 2001;12:397-408.

5 Johnson JA, Gangemi JD: Selective inhibition of human papillomavirus-induced cell proliferation by (S)-1-[3-hydroxy-2-(phosphonylmethoxy)propyl]-cytosine. Antimicrob Agents Chemother 1999;43:1198-1205.

-6 Snoeck R, Wellens W, Desloovere C, Van Ranst M, Naesens L, De Clercq E, Feenstra L: Treatment of severe laryngeal papillomatosis with intralesional injections of cidofovir. J Med Virol 1998;54:219-225.

-7 Beadle JR, Hartline C, Aldern KA, Rodriguez N, Harden E, Kern ER, Hostetler KY: Alkoxyalkyl esters of cidofovir and cyclic cidofovir exhibit multiple-log enhancement of antiviral activity against cytomegalovirus and herpesvirus replication in vitro. Antimicrob Agents Chemother 2002;46:23812386.
$>8$ Kern ER, Hartline C, Harden E, Keith K, Rodriguez N, Beadle JR, Hostetler KY: Enhanced inhibition of orthopoxvirus replication in vitro by alkoxyalkyl esters of cidofovir and cyclic cidofovir. Antimicrob Agents Chemother 2002;46:991-995.

$\checkmark 9$ Hartline CB, Gustin KM, Wan WB, Ciesla SL, Beadle JR, Hostetler KY, Kern ER: Activity of lipid-ester prodrugs of acyclic nucleoside phosphonates: activity against adenovirus replication in vitro. J Infect Dis 2005;191: 396-399.

10 Wan WB, Beadle JR, Hartline CB, Kern ER, Ciesla SL, Valiaeva N, Hostetler KY: Comparison of the antiviral activity of alkoxyalkyl and alkyl esters of cidofovir against human and murine cytomegalovirus replication in vitro. Antimicrob Agents Chemother 2005;49:656-662.

11 Aldern KA, Ciesla SL, Winegarden KL, Hostetler KY: Increased antiviral activity of 1-O-hexadecyloxypropyl- $\left[2-{ }^{14} \mathrm{C}\right]$ cidofovir in MRC-5 human lung fibroblasts is explained by unique cellular uptake and metabolism. Mol Pharmacol 2003;63:678-681.

12 Hostetler KY, Aldern KA, Wan WB, Ciesla SL, Beadle JR: Alkoxyalkyl esters of (S)-9-[3hydroxy-2-(phosphonomethoxy)propyl]adenine are potent inhibitors of the replication of wild-type and drug-resistant human immunodeficiency virus type 1 in vitro. Antimicrob Agents Chemother 2006;50:28572859.

13 Magee WC, Aldern KA, Hostetler KY, Evans DH: Cidofovir and (S)-9-[3-hydroxy-(2phosphonomethoxy)propyl]adenine are highly effective inhibitors of vaccinia virus DNA polymerase when incorporated into the template strand. Antimicrob Agents Chemother 2008;52:586-597.

-14 Hostetler KY: Alkoxyalkyl prodrugs of acyclic nucleoside phosphonates enhance ora antiviral activity and reduce toxicity: current state of the art. Antiviral Res 2009;82 A84-A98.
15 Valiaeva N, Beadle JR, Aldern KA, Trahan J, Hostetler KY: Synthesis and antiviral evaluation of alkoxyalkyl esters of acyclic purine and pyrimidine nucleoside phosphonates against HIV-1 in vitro. Antiviral Res 2006; 72:10-19.

16 Robbins BL, Connelly MC, Marshall DR, Srinivas RV, Fridland A: A human $T$ lymphoid cell variant resistant to the acyclic nucleosidephosphonate9-(2-phosphonylmethoxyethyl)adenine shows a unique combination of a phosphorylation defect and increased efflux of the agent. Mol Pharmacol 1995;47:391-397.

17 Rose WC, Crosswell AR, Bronson JJ, Martin JC: In vivo antitumor activity of 9-[(2-phosphonylmethoxy)ethyl]guanine and related phosphonate nucleotide analogues. J Natl Cancer Inst 1990;82:510-512.

18 Pisarev VM, Lee S-H, Connelly MC, Fridland A: Intracellular metabolism and action of acyclic nucleoside phosphonates on DNA replication. Mol Pharmacol 1997;52:63-68.

19 Kramata P, Downey KM, Paborsky LR: Incorporation and excision of 9-(2-phosphonylmethoxyethyl)guanine (PMEG) by DNA polymerase $\delta$ and $\varepsilon$ in vitro, J Biol Chem 1998;273:21966-21971.

$>20$ Tsai C-Y, Ray AS, Tumas DB, Keating MJ, Reiser $\mathrm{H}$, Plunkett $\mathrm{W}$ : Targeting DNA repair in chronic lymphocytic leukemia cells with a novel acyclic nucleoside analogue, GS9219. Clin Cancer Res 2009;15:3760-3769.

21 Wolfgang GH, Shibata R, Wang J, Ray AS, Wu S, Doerrfler E, Reiser H, Lee WA, Birkus G, Christensen ND, Andrei G, Snoeck R: GS9191 is a novel topical prodrug of the nucleotide analog 9-(2-phosphonylmethoxyethyl)guanine with antiproliferative activity and possible utility in the treatment of human papillomavirus lesions. Antimicrob Agents Chemother 2009;53:2777-2784. 